\title{
Maternal height, shoe size, and outcome of labour in white primigravidas: a prospective anthropometric study
}

\author{
Tahir A Mahmood, Doris M Campbell, Alex W Wilson
}

\begin{abstract}
A total of 563 white primigravid patients at Raigmore Hospital, Inverness, were recruited in a prospective study to examine the association between maternal height, shoe size, and the outcome of labour. There was a significantly increased caesarean section rate in women of short stature but no association between mode of delivery and shoe size. Babies born vaginally had heavier birth weights with increasing height and shoe size. Babies born by caesarean section were heavier than those born vaginally, but their birthweight showed no relation with either height or shoe size.

Shoe size is not a useful clinical predictor for the probability of cephalopelvic disproportion, and, although maternal height is a better clinical guide to pelvic adequacy in labour, $80 \%$ of mothers less than $160 \mathrm{~cm}$ tall delivered vaginally. A well conducted trial of labour should be considered in all primigravid patients with cephalic presentation irrespective of maternal height or shoe size if no obstetric complication exists.
\end{abstract}

\section{Introduction}

A pregnant woman's height has routinely been recorded on her obstetric case record since studies showed a relation between maternal height, pelvic dimension, and the outcome of pregnancy. ${ }^{1.5}$ Another piece of routinely recorded information is the woman's shoe size. In a series of 75 patients of mixed parity Kennedy and Greenwald claimed that a shoe size of $51 / 2$ or more was a surrogate measure of pelvic adequacy, especially when the mother was less than 1.52 metres tall," but their analysis and conclusions have been criticised. ${ }^{7}$ In a larger study of 351 women of mixed parity and of different ethnic origin Frame et al found an incidence of caesarean section of $21 \%$ when the woman's shoe size was less than $4 \frac{1}{2}, 10 \%$ when it was $41 / 2$ to 6 , and only $1 \%$ when it was $6^{1 / 2}$ or more, ${ }^{8}$ but in their series the woman's height was not a useful predictor of ceasarean section. Pelvic dimensions and shapes vary between ethnic groups, ${ }^{9}$ however, and the incidence of ceasarean section differs between primigravidas and parous patients.

We therefore performed a prospective study among Department of Obstetric and Gynaecology, Raigmore Hospital, Inverness

Tahir A Mahmood, MRCOG, senior registrar

Department of Obstetrics and Gynaecology and Reproductive Physiology, Maternity Hospital, Aberdeen AB9 2ZD

Doris M Campbell, FRCOG, senior lecturer

School of Mathematical Sciences and Computer Studies, Robert Gordon's Institute of Technology Alex W Wilson, FSs, senior lecturer

Correspondence to: Dr T A Mahmood, Aberdeen Maternity Hospital.

\section{Patients and methods}

Six hundred consecutive white primigravid patients who booked for confinement at Raigmore Hospital, Inverness, were recruited. All patients underwent ultrasonic gestational assessment before 20 weeks' gestation. At the booking visit the patient's height and shoe size were recorded. In the absence of obstetric complications a spontaneous onset of labour was awaited. In those patients who failed to go into labour by 12 days after their expected date of delivery induction of labour using prostaglandin vaginal pessaries $(3 \mathrm{mg}$ ) was carried out; when in labour forewater amniotomy was performed. Intravenous oxytocin augmentation was started if progress in labour was less than satisfactory (cervical dilatation less than $1 \mathrm{~cm} /$ hour). Cervical scoring was carried out either at the time of forewater amniotomy or at the time of first vaginal examination in patients admitted in spontaneous labour. A cervical score of less than 4 was considered to be "unfavourable."

After delivery a record was made of duration of labour, mode of delivery, and birthweight.

Cephalopelvic disproportion was diagnosed when there was evidence of either $(a)$ a prolonged first stage $(>12$ hours) in spite of effective uterine activity or (b) failure of the head to descend or evidence of severe moulding or fetal distress in late first stage with secondary arrest or prolonged second stage. In patients with a prolonged second stage Kielland's forceps delivery was attempted only in theatre with facilities at hand for an immediate caesarean section.

All patients delivered using forceps (whether rotational, non-rotational, or low cavity) were included in the vaginal delivery group.

Both shoe size and height were grouped in five subsets- $\leqslant 31 / 2 ; 4-41 / 2 ; 5-51 / 2 ; 6-61 / 2 ; \geqslant 7$ and $\leqslant 153 \mathrm{~cm}$, $154-159 \mathrm{~cm}, 160-165 \mathrm{~cm}, 166-171 \mathrm{~cm}, \geqslant 172 \mathrm{~cm}$. This gave a fairly symmetrical set of frequencies. Statistical analyses were carried out using the Minitab statistical package.

\section{Results}

Of the 600 patients, $37(6 \%)$ were excluded from the final analysis because they did not meet our criteria for inclusion (singleton pregnancy, cephalic presentation, and pregnancy progressing beyond 34 weeks) or for other reasons (table I). Of the remaining 563 patients, 489 delivered vaginally (433 spontaneously, 42 (9\%) with non-rotational forceps and $14(3 \%)$ with rotational forceps), and 74 (13\%) required emergency caesarean section with a diagnosis of cephalopelvic disproportion in the course of labour.

The mean gestational age at delivery was 39.8 (SD 1.49) weeks, the mean maternal height 161.63 $(6 \cdot 11) \mathrm{cm}$, and mean shoe size 5.08 (1.13). Linear regression analysis confirmed as expected a strong correlation between maternal height and shoe size $(\mathrm{r}=0.649$; height $=144+3 \cdot 50$ shoe size $)$.

Outcome of labour by maternal height-Maternal height in those delivering vaginally (mean 162.02 $(6.03) \mathrm{cm})$ was significantly greater than in those requiring caesarean section (mean 159.03 $(6.07) \mathrm{cm}$; $t=3.98 ; \mathrm{p}<0.001)$. With increasing maternal height there was a significant decline in the proportion of patients delivering by caesarean section but no significant difference in the rates of induction or unfavourable cervix in labour (table II). Table III gives

Total No (\%) of patients
No (\%) excluded from analysis:
Spontaneous abortion
Preterm labour
Intrauterine growth retardation
Elective section for severe pre-eclamptic toxaemia,
failed induction, abnormal cardiotocograph
Emergency caesarean section for fetal distress (abruptio,
cord prolapse, intrauterine growth retardation) in
early labour
Twins
Breech, oblique lie
Placenta praevia

Total analysed
TABLE I-Details of patients excluded from analysis 
the mean duration of labour for those delivering vaginally and the mean birthweights for both delivery groups by maternal height. Analysis of variance indicated that the length of labour did not vary with maternal height. As expected, the mean birthweight was higher as height increased among those delivering vaginally, although this was not so in those requiring caesarean section. The birthweights of babies born by

TABLE II-Outcome of labour according to maternal height and shoe size. Results are numbers (and percentages) of women

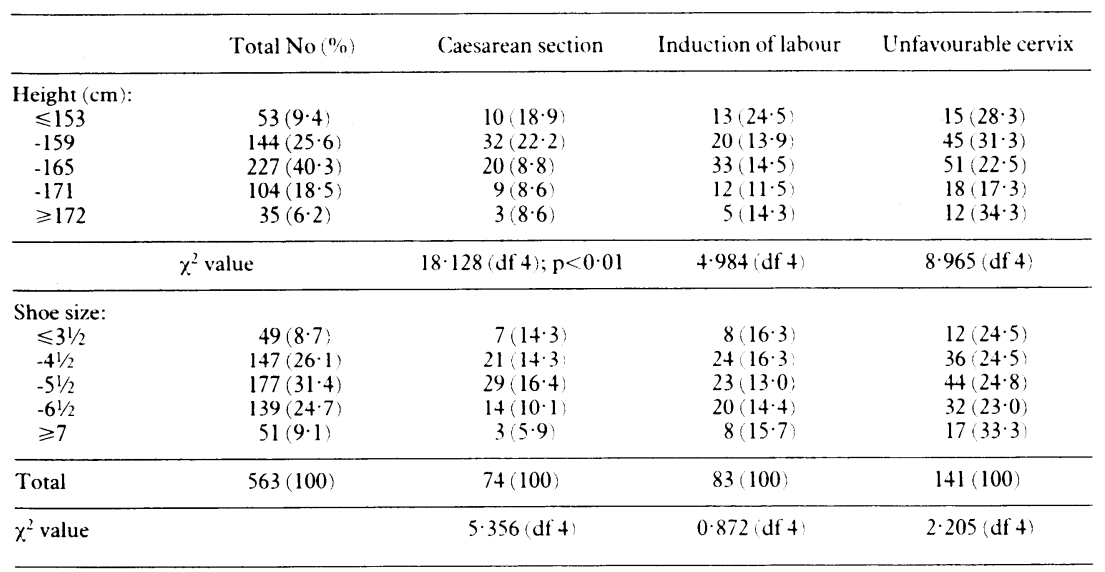

TABLE III-Mean duration of labour in infants delivered vaginally and birthweights of those delivered vaginally and by caesarean section according to maternal height and shoe size. Results are means (and standard deviations)

\begin{tabular}{|c|c|c|c|c|c|c|}
\hline & \multicolumn{2}{|c|}{$\begin{array}{l}\text { Duration of labour } \\
\text { (hours) for vaginal } \\
\text { delivery only }\end{array}$} & \multicolumn{2}{|c|}{$\begin{array}{l}\text { Birthweight }(\mathrm{kg}) \text { of } \\
\text { babies delivered } \\
\text { vaginally }\end{array}$} & \multicolumn{2}{|c|}{$\begin{array}{c}\text { Birthweight }(\mathrm{kg}) \text { of babies } \\
\text { delivered by caesarean } \\
\text { section }\end{array}$} \\
\hline & Mean (SD) & No & $\operatorname{Mean}(\mathrm{SD})$ & No & Mean $(\mathrm{SD})$ & No \\
\hline \multicolumn{7}{|l|}{ Height $(\mathrm{cm})$ : } \\
\hline$\leqslant 153$ & $9 \cdot 30(3.29)$ & 32 & $3.20(0.56)$ & 43 & $3.68(0.64)$ & 10 \\
\hline-159 & $10 \cdot 21(3.99)$ & 112 & $3.34(0.42)$ & 112 & $3.60(0.47)$ & 32 \\
\hline-165 & $9 \cdot 11(3.74)$ & 207 & $3.44(0.46)$ & 207 & $3.70(0.37)$ & 20 \\
\hline-171 & $9.37(3.77)$ & 95 & $3.52(0.43)$ & 95 & $3.86(0.62)$ & 9 \\
\hline$\geqslant 172$ & $9 \cdot 96(3 \cdot 79)$ & 32 & $3.52(0.55)$ & 32 & $3.89(0.59)$ & 3 \\
\hline Analysis of variance $(\mathbf{F})$ & \multicolumn{2}{|c|}{1.61} & \multicolumn{2}{|c|}{$4.83(p<0.001)$} & \multicolumn{2}{|c|}{0.67} \\
\hline \multicolumn{7}{|l|}{ Shoe size: } \\
\hline$\leqslant 31 / 2$ & $8.88(3.28)$ & 42 & $3.29(0.45)$ & 42 & $3.63(0.45)$ & 7 \\
\hline$-41 / 2$ & $9.34(3.79)$ & 126 & $3.28(0.45)$ & 126 & $3.50(0.53)$ & 21 \\
\hline$-51 / 2$ & $9.35(3.51)$ & 148 & $3.43(0.44)$ & 148 & $3.79(0.43)$ & 29 \\
\hline$-6^{1 / 2}$ & $9.54(3.99)$ & 125 & $3.51(0.45)$ & 125 & $3.78(0.57)$ & 14 \\
\hline$\geqslant 7$ & $10 \cdot 42(4 \cdot 34)$ & 48 & $3.59(0.54)$ & 48 & $3.57(0.33)$ & 3 \\
\hline Analysis of variance $(F)$ & \multicolumn{2}{|c|}{0.33} & \multicolumn{2}{|c|}{$6.92(p<0.001)$} & \multicolumn{2}{|c|}{$1 \cdot 26$} \\
\hline
\end{tabular}

TABLE IV-Correlation coefficients $(r)$ between pelvic dimensions and maternal height and shoe size

\begin{tabular}{lcccc}
\hline Variable & Anteroposterior inlet & Transverse inlet & Bispinous & Anteropostérior outlet \\
\hline Height & $0 \cdot 246^{\star}$ & $0 \cdot 321 \dagger$ & $0 \cdot 046$ & $0 \cdot 248$ \\
Shoe size & $0 \cdot 108$ & $0 \cdot 280^{\star}$ & $0 \cdot 066$ & $0 \cdot 292 \ddagger$
\end{tabular}

${ }^{\star} \mathrm{p}<0 \cdot 05 ; \mathrm{p} \mathbf{p}<0 \cdot 01 ; \neq \mathrm{p}<0 \cdot 02$.

TABLE V-Pelvic measurements $(\mathrm{cm})$ by shoe size and height. Values are means (and standard deviations)

\begin{tabular}{|c|c|c|c|c|}
\hline & Anteroposterior inlet & Transverse diameter inlet & Bispinous & Anteroposterior outlet \\
\hline $\begin{array}{l}\text { Shoe size }(n=70) \text { : } \\
\quad \leqslant 41 / 2(n=28) \\
-51 / 2(n=25) \\
\geqslant 6(n=17)\end{array}$ & $\begin{array}{l}11.32(0.86) \\
11.55(0.48) \\
11.66(0.62)\end{array}$ & $\begin{array}{l}12.69(0.46) \\
12.87(0 \cdot 44) \\
12.95(0.38)\end{array}$ & $\begin{array}{l}9.79(0.53) \\
9.82(0.45) \\
9.92(0.50)\end{array}$ & $\begin{array}{l}10.92(0.57) \\
10.97(0.63) \\
11.29(0.49)\end{array}$ \\
\hline Analysis of variance $(\mathbf{F})$ & $1 \cdot 51$ & $2 \cdot 11$ & $0 \cdot 38$ & $2 \cdot 46$ \\
\hline $\begin{array}{c}\text { Height }(n=70) \text { : } \\
\quad \leq 153(n=10) \\
-159(n=29) \\
-165(n=19) \\
-178(n=12)\end{array}$ & $\begin{array}{l}10.99(0.62) \\
11.52(0.79) \\
11.55(0.56) \\
11.70(0.47)\end{array}$ & $\begin{array}{l}12 \cdot 49(0.26) \\
12 \cdot 81(0.49) \\
12 \cdot 90(0.41) \\
12.97(0.39)\end{array}$ & $\begin{array}{l}9.90(0.61) \\
9 \cdot 86(0.46) \\
9.67(0.39) \\
9.97(0.60)\end{array}$ & $\begin{array}{l}10.90(0.26) \\
10.97(0.69) \\
11.04(0.55) \\
11.26(0.57)\end{array}$ \\
\hline Analysis of variance $(F)$ & $2 \cdot 29$ & $2 \cdot 71$ & $1 \cdot 15$ & 0.89 \\
\hline
\end{tabular}

caesarean section were greater than those of the babies delivered vaginally.

Outcome of labour in relation to shoe size-There was no significant difference $(t=1.53)$ in mean shoe size between the vaginal delivery group (mean $5 \cdot 11(1 \cdot 4)$ ) and the caesarean section group (mean $4 \cdot 90(1 \cdot 05)$ ), and there was no significant differences by shoe size in the rates of caesarean section, induction of labour, or unfavourable cervix (table II). Table III gives the mean duration of labour for those delivered vaginally and the mean birthweights for both delivery groups by shoe size groups. Analysis of variance indicated that the mean length of labour did not vary with shoe size. The babies were significantly heavier with increasing shoe size among those delivering vaginally, but those delivered by caesarean section did not show this pattern.

Postnatal pelvimetry-Of the 74 patients delivered by caesarean section 70 had postnatal radiographic pelvimetry carried out. Since the number of patients in subgroups of shoe size were small they were therefore grouped together as $\leqslant 41 / 2,5-51 / 2$, and $\geqslant 6$. Similarly, there were very few women in the upper two height groups and they were combined into one group $(166-178 \mathrm{~cm})$. Table IV confirms that there were significant correlations between maternal height and shoe size and pelvic measurements, although not with all. With grouped data for both height and shoe size (table V), however, no differences were apparent.

\section{Discussion}

This study was designed to assess the value of recording maternal shoe size and height in obstetric case records. We studied only healthy white primigravidas, thereby overcoming the problems in earlier studies. We excluded those patients who had an elective caesarean section carried out because of obstetric complications and also those delivered by emergency caesarean section in early labour where cephalopelvic disproportion did not appear to be an underlying cause. Women going into preterm labour and also those with intrauterine growth retardation were excluded because of the increased inherent risk of emergency sections owing to smaller fetal size and placental factors. Similarly, women with breech presentation were excluded because their management is still controversial, some obstetricians attempting vaginal delivery and others performing elective caesarean section.

The data from our series, which is the largest reported to date, suggest that patients less than $160 \mathrm{~cm}$ tall are at increased risk of undergoing caesarean section for cephalopelvic disproportion. No such trend was obvious when shoe size alone was used as a predictor of the outcome of labour; our findings thus disagree with those of Frame et al. ${ }^{\times}$Although maternal height is a more useful guide to the outcome of labour even in mothers less than $160 \mathrm{~cm}$ tall most $(80 \%)$ would deliver vaginally.

Although only 70 patients underwent postnatal radiographic pelvimetry, maternal height was more strongly associated with pelvic inlet measurements whereas shoe size showed a significant relation with one diameter of both pelvic inlet and outlet. These observations are clinically important because Schwartz et al reported a stronger correlation between inlet disproportion and mode of delivery than between midplane disproportion and outcome. "Isolated pelvic outlet contraction is extremely rare." Furthermore, the pelvic outlet increases up to $30 \%$ in the squatting position. ${ }^{13}$ Therefore these data further support our earlier conclusion that maternal height is a better indicator than shoe size.

We considered other factors that may adversely 
affect labour such as an unfavourable cervix and induction,,$^{10}$ and found no difference in these among either height or shoe size subgroups, thus adding weight to the conclusion that the high caesarean section rates for disproportion in mothers less than $160 \mathrm{~cm}$ tall are real observations.

The longheld belief that maternal stature and shoe size have an important bearing on the outcome of labour should be modified. A well conducted trial of labour should be considered in all primigravidas with cephalic presentation irrespective of maternal height or shoe size unless obstetrically contraindicated.

We thank Drs Lees, Hulse, MacLean, and Milne, consultant obstetricians at Raigmore Hospital, Inverness, for allowing their patients to be studied; Sister Jean Campbell and Staff Midwives Linda Thomson and Hilary Munro at the antenatal clinic for recruiting the patients; Mr A A Smith, statistician, for interim analyses; Professor A A Templeton for helpful suggestions; and Mrs Irene Morrison for secretarial help.
1 Baird D. Secial factors in obstetrics. Lancet 1949; i: 1079-83

2 Bernard R.M. The shape and size of the female pelvis. Edinhurgh . Medical Joumal 1952:59:1.9.

Walker J. Prolonged pregnancy sundrome. Am 7 Obstet (jinecol 1958;76 $1231-47$.

+ Garrey M, Govan OAT, Hodge C, Callender R, eds. Obstetrics illustruted. Edinburgh: (hurchill Livingstone, 1973.

5 Donald I. Practical obstetrical problems. 5 th ed. London: Llovd-Luke, 1979.

6 Kennedy JL. Greenwald E. Correlation of shoe size and obstetric outcome Am fOhstet (ivinecol 1981;140:466-7.

7 Munice HL. Relationship of shoe size and cephalopelvic disproportion. Am. 7 Obstet (ivnecol 1982;142:931-2

8 Frame S, Merre J, Peters A, Hall D. Maternal height and shoe size as predictor of pelvic disproportion: an assessment. Br $\mathcal{F}$ Obstet Gynaecol 1985;92 $1239-45$.

9 Molov HC. Evaluation of the pelies in obstetrics. Philadelphia: Saunders, 1951. 10 Calder AA, Embrey MP, Hillier K. Extra-amniotic prostaglandin E, for the induction of labour at term. Foumal of Obstetrics and (jynaecology of the British Commonivealth 1974:81:39-46.

11 Schwart\% (iS, Kirkpatrick RH. Tovell HMM. Correlation of cephalopelvimetry to obstetrical outcome with special reference to radiologic pelvimetry to obstetrical outcome with
disproportion. Rudiologv 1956:67:856-62.

12 Mener WF Estimation of pelvic canacity J111:1 1948:138:169-74.

13 Russel JGB. Moulding of the pelvic outlet. Foumal of Obstetrics and Gynaecologv' of the British Commonwealth 1969;76:817-20.
Department of Community

Health, School of

Medicine, University of

Auckland, New Zealand, and Department of

Radiology and Coronary

Care Unit, Green Lane

Hospital, Auckland,

New Zealand

Alistair W Stewart, BSC, research officer

John Fraser, FRCR, cardiac

radiologist

Robin $M$ Norris, FRCP, honorary professor of

cardiovascular therapeutics

Robert Beaglehole, MD,

professor of community health

Correspondence to: $\mathrm{MrAW}$ Stewart, Department of

Community Health, School

of Medicine, University of

Auckland, Auckland, New

Zealand.

\title{
Changes in severity of myocardial infarction and three year survival rates after myocardial infarction in Auckland, 1966-7 and 1981-2
}

\author{
Alistair W Stewart, John Fraser, Robin M Norris, Robert Beaglehole
}

\section{Abstract}

Mortality from coronary heart disease has been declining steadily over the past 20 years in Auckland. The possibility that improved survival contributed to this decline was examined in patients who survived four weeks after myocardial infarction, changes in the severity of the disease being controlled for. Patients who had had myocardial infarction in 1966-7 (191 patients) or 1981-2 (203) were compared to determine whether three year survival rates had changed and the severity of the disease altered. With a coronary prognostic index taken as the measure of severity the 1981-2 group had significantly more severe myocardial infarctions than the 1966-7 group, but despite this the three year survival was significantly better $(86 \%$ in the $1981-2$ group $v 75 \%$ in the 1966-7 group).

These findings suggest that improved survival after myocardial infarction contributed to the decline in mortality.

\section{Introduction}

Mortality from coronary heart disease has been decreasing in New Zealand at roughly $2 \%$ a year since $1968,{ }^{\prime}$ and this could be due to a decreasing incidence of the disease or of fatal cases, or both. In Auckland during 1974-81 the rate of acute myocardial infarction did not decrease ${ }^{2}$ and one and three year survival after infarction did not show a clear improvement, ${ }^{3+}$ although the rate of sudden death from coronary causes declined steadily. ${ }^{2}$ We compared the three year survival rates after myocardial infarction in 1966-7 and 1981-2, taking into account changes in the severity of the illness over this time.

\section{Patients and methods}

1966-7-We used a subset of data from all 757 patients with acute myocardial infarction admitted to the three hospitals in Auckland between March 1966 and February 1967. ${ }^{5}$ The severity of infarction was measured as the coronary prognostic index, which is derived from the patient's age; size of the heart and state of the lung, assessed from an $x$ ray film of the chest at the time of infarction; and history of myocardial infarction." The coronary prognostic index was calculated for each of the patients at admission. We obtained information on the patients' survival to three years from their general practitioners or by other methods. ${ }^{6}$ Complete records from 1966-7 were available only on patients who were discharged from hospital. As the average time to discharge fell considerably between 1967 and 1981 the day of discharge was not a useful starting time for this study. Therefore we arbitrarily chose to study the patients who survived for four weeks after their myocardial infarction. This meant that 191 patients were studied.

1981-2 - The patients studied in 1981-2 came from a register of all patients in Auckland aged less than 70 with definite myocardial infarction according to the criteria of the World Health Organisation. ${ }^{7}$ We obtained information on the patients' survival to three years by contacting the patients, their relatives, or their general practitioner. ${ }^{+}$Information on the size of the heart and state of the lungs for estimating the coronary prognostic index was obtained by one of us (JRF), who reviewed all chest $x$ ray films taken on the day of admission to hospital. ${ }^{6}$ As the films were available only at one hospital, only patients admitted to this hospital who survived for four weeks were considered for study. This limitation resulted in the study group comprising 233 patients.

Survival rates were calculated by the Kaplan-Meier life table method, initially without regard to the coronary prognostic index, and the rates were compared by the log rank test. The chance of dying compared with a reference group was calculated by fitting a model with proportional hazards general linear regression. ${ }^{x}$

\section{Results}

Among the 233 patients with a myocardial infarction in $1981-2$, the $x$ ray film obtained at admission could not be traced for $30(13 \%)$, and hence in these patients 